\title{
CIRCULACIÓN MONETARIA EN URSO: MATERIAL NUMISMÁTICO \\ RECUPERADO EN LA INTERVENCIÓN ARQUEOLÓGICA \\ DE CALLE LA HUERTA 3 Y 5 DE OSUNA (SEVILLA)
}

\section{CURRENCY CIRCULATION AT URSO. NUMISMATIC MATERIAL RECOVERED FROM THE ARCHAEOLOGICAL INTERVENTION AT No 3 AND 5 OF LA HUERTA STREET (OSUNA, SEVILLA)}

por

\author{
ÁlVARO FERNÁNDEZ FLORES * \\ JOSÉ ILDEFONSO RUIZ CECILIA **
}

\begin{abstract}
RESUMEN En el presente artículo se ofrece un estudio y valoración del material numismático recuperado en los trabajos arqueológicos realizados en las parcelas $n^{\circ} 3$ y 5 de la calle La Huerta de Osuna, prestando especial interés al contexto arqueológico en el que se encontraron. La gran mayoría de las piezas pertenecen cronológicamente a la época tardorromana, si bien se recogen ejemplares del siglo I a. C. y del siglo XVI.
\end{abstract}

\begin{abstract}
In this article we offer a study and an assessment of the numismatic material obtained from the archaeological work carried out on sites 3 and 5 in La Huerta Street in Osuna. It has special interest in the archaeological context in which the material was found. Most of the pieces date from the late Roman period, although there are also some which are from the 16th Century ${ }^{* * *}$.
\end{abstract}

Palabras claves Urso, numismática, contexto estratigráfico, circulación monetaria, periodización cronocultural.

Key words

Urso, numismatics, stratigraphic context, currency circulation, chronological and cultural periodization.

\section{INTRODUCCIÓN}

El hallazgo de monedas dentro una intervención arqueológica resulta de suma importancia en tanto que su recuperación, dentro de un contexto deposicional o constructivo determinado, ofrece al arqueólogo

\footnotetext{
* affarquio@mixmail.com

** joseidelfonso@telefonica.net

*** Traducción del resumen y palabras clave por Laura Moreno de Soto, a quien agradecemos su amabilidad.
} 
una datación complementaria y/o alternativa a la ofrecida por el material cerámico. Pero al margen de la datación, el propio estado de conservación de las piezas, sus marcas, lugares de acuñación, su contexto en la intervención y su misma dispersión dentro de una unidad estratigráfica, pueden ofrecer datos que el numísmata y el arqueólogo han de saber conjugar e interpretar con objeto de contextualizar dentro de un marco histórico amplio los resultados de la intervención.

A partir de la fusión de los datos ofrecidos por el material numismático, la arqueología y los textos escritos (fuentes y bibliografía consultada) pretendemos ofrecer, dentro de una problemática histórica general, parte de los resultados de la excavación. Al mismo tiempo, la publicación del conjunto de monedas recuperado supondrá una aportación al material de trabajo disponible para el conocimiento histórico de Osuna.

\section{LA INTERVENCIÓN ARQUEOLÓGICA}

\section{II.1. Motivos de la intervención}

La Intervención Arqueológica de Urgencia en que se recuperaron los materiales objeto de estudio se llevó a cabo en la calle La Huerta n 3-5 de la villa de Osuna (Sevilla), entre el 21 de Junio y el 12 de Julio de 1999 (Fig. 1). La actuación estuvo motivada por la edificación de un bloque de viviendas de nueva planta, dotado de garaje subterráneo, cuya construcción afectaría al substrato arqueológico hasta una cota media de $-2,70 \mathrm{~m}$ por debajo de la rasante del terreno. Esta circunstancia hizo necesaria una intervención arqueológica que, con carácter de urgencia, permitiese documentar, estudiar y valorar el registro arqueológico presente ${ }^{1}$.

\section{II.2. Ubicación del solar}

El solar afectado está formado por las parcelas $n^{\circ} 3$ y 5 de la calle La Huerta de Osuna (Sevilla). El inmueble se halla situado en pleno casco histórico de Osuna, dentro de la manzana delimitada al oeste por la calle Arcipreste Valderrama y la plaza del Duque, al sur por la calle Santa Clara, al este por Asistente Arjona y al norte por la calle La Huerta (Fig. 2)

\section{II.3. Problemática Histórico-Arqueológica del solar}

\section{II.3.A. Contexto global}

Osuna se asienta sobre un cerro a media ladera dominando gran parte de la campiña sevillana. La mayor altitud del promontorio se encuentra hacia el noreste del actual casco urbano. En un lugar intermedio entre esa cota máxima y la actual población se encuentra el núcleo principal de la ciudad de Urso y la posterior Colonia Iulia Genetiua. De la ciudad prerromana y romana existen numerosos testimonios; no así del periodo visigodo e islámico, momento en que la ciudad parece realizar un progresivo desplazamiento situándose a los pies del núcleo romano. Los límites de la ciudad en estos periodos se situarían al oeste del caserío actual (Vargas, Romo y García 1993: 52) (Fig. 1).

1. Las tareas fueron dirigidas por D. José Ildefonso Ruiz Cecilia, contando con D. Álvaro Fernández Flores como arqueólogotécnico. La Memoria Científica de la Intervención, de la que se extraen los datos que sirven de base al presente artículo, fue realizada en colaboración por ambos arqueólogos (Ruiz Cecilia y Fernández Flores 1999a). 


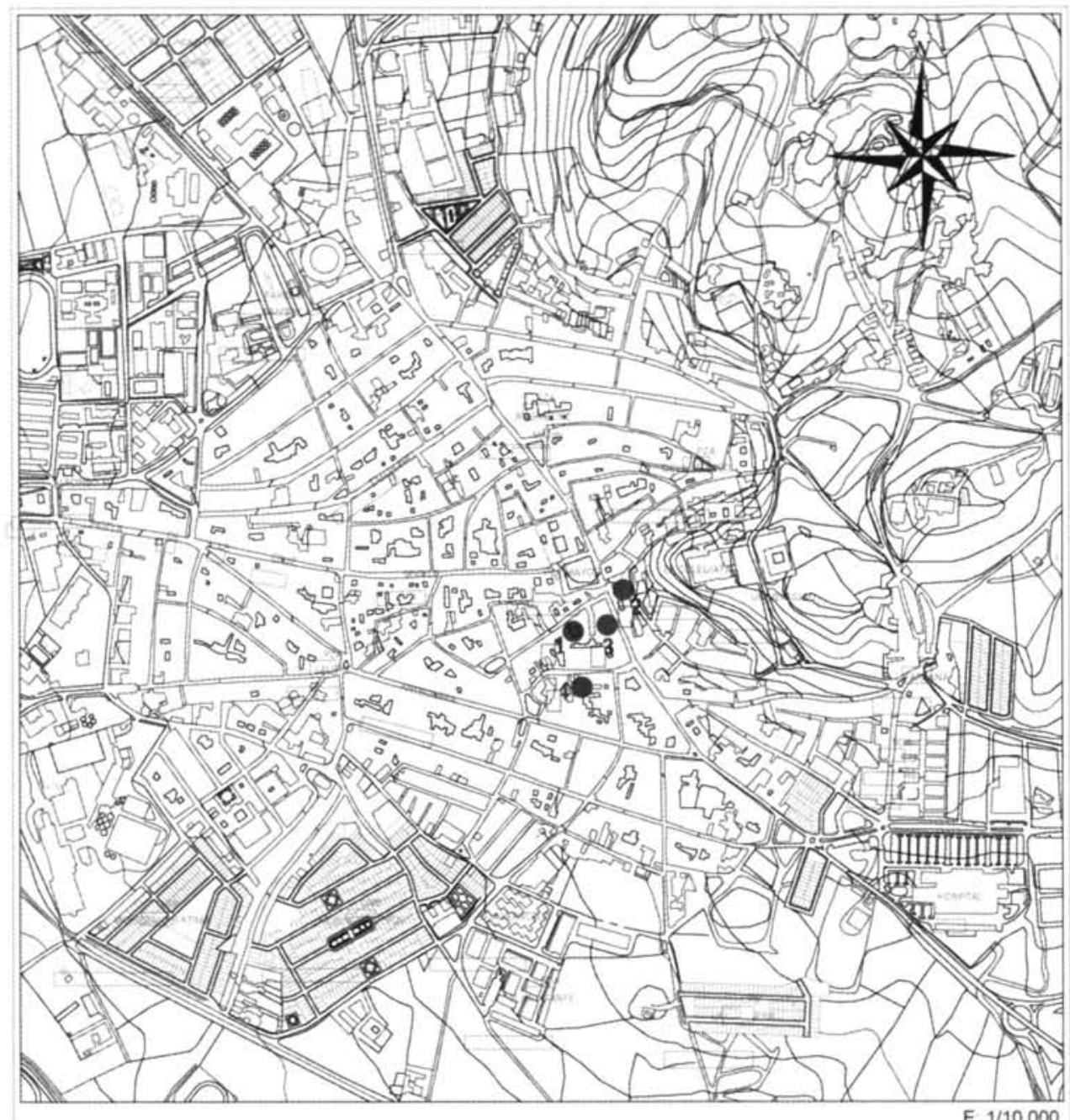

UBICACIÓN DEL SOLAR EN EL CONJUNTO URBANO Y LOCALIZACIÓN DE LAS INTERVENCIONES ARQUEOLOGICAS MÁS CERCANAS

10 CALLE LA HUERTA N 3 y 5

2 TORRE DEL AGUA

3 CALle ASISTENTE ARJONA N N 6 y 8

4 - CALLE TESOREROS N $N^{\circ} 6$

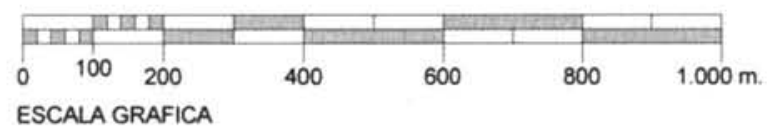

Fig. 1. Plano Osuna

ISSN: 1133-4525 ISSN-e: 2255-3924 


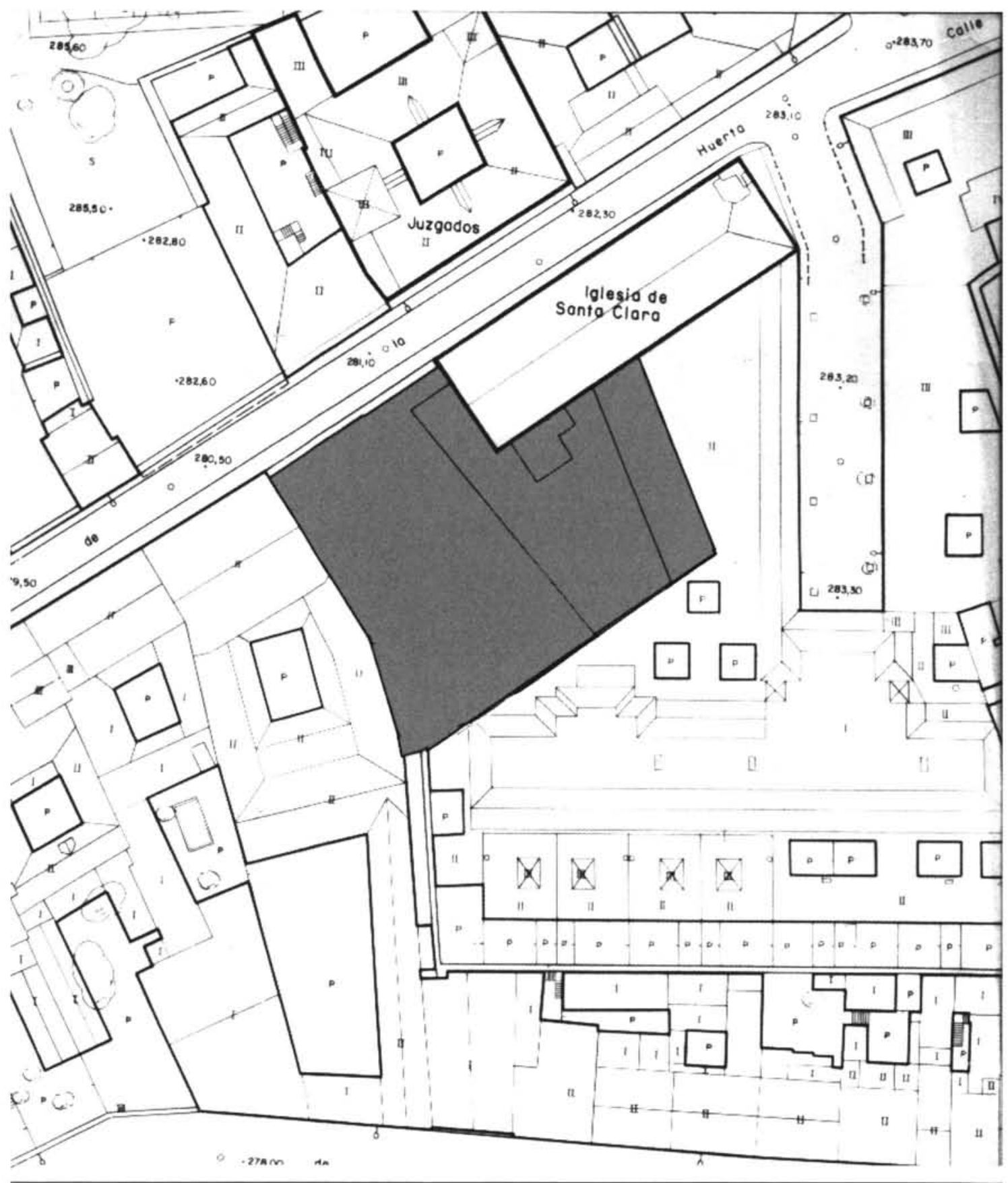

UBICACIÓN DEL INMUEBLE EN EL PARCELARIO ACTUAL.

PARCELAS AFECTADAS POR EL PROYECTO DE CONSTRUCCIÓN.

\section{I.A.U. C/ HUERTA 3 Y 5, OSUNA. FIGURA: 2}

Fig. 2. Parcelario 
Este fenómeno se explica porque hacia el este la caída de la elevación es abrupta, mientras que en el sentido contrario es mucho más suave; por tanto la tendencia en el crecimiento urbanístico ha estado dirigida, de forma general, hacia el oeste. La ciudad se fue trasladando ladera abajo en un proceso que perdura hasta la actualidad y que ha dado lugar a un fenómeno que algunos investigadores han denominado como ciudades intersectadas (Jiménez Barrientos y Salas Álvarez 1997: 9-10).

Los datos de la ciudad medieval son escasos, aún así se nos muestra una ciudad fortificada de cierta importancia estratégica, por ser comunicación entre la campiña y la serranía de Antequera.

A partir del siglo XVI la ciudad conoce un gran desarrollo en todos los sentidos que se traduce en la ocupación y urbanización del espacio extramuros, siempre siguiendo las laderas situadas al oeste, y el progresivo abandono de las zonas más altas e intramuros -tal y como queda documentado tanto por las fuentes escritas (Ledesma Gámez 1998: 139) ${ }^{2}$ como arqueológicas (Ruiz Cecilia 1998: 1062-1073)-.

A partir del siglo XIX la ciudad entra en crisis y se frena su expansión para, en los últimos decenios, experimentar un nuevo crecimiento hacia el sureste de tipo industrial y reocupar las zonas más altas (Lerdo de Tejada et alii 1992:124-125).

\section{II.3.B. Contexto urbano}

El solar se encuadra en la zona central del actual casco urbano de Osuna, al oeste del área ocupada por el núcleo originario e incluso extramuros de la ciudad medieval, aunque no demasiado alejado de la antigua Puerta del Agua. Los datos recuperados en las intervenciones arqueológicas cercanas (Salas Álvarez y Pérez Rangel 1988: 386-391; Sánchez Gil de Montes y Salas Álvarez 1996: 677-687) muestran una zona con un posible poblamiento disperso en época romana que, tras un largo paréntesis, vuelve a ocuparse durante el periodo almohade aunque con carácter transitorio. Tras la conquista se registra un hiato poblacional en que la zona parece estar destinada a huertas -de ahí el nombre de la calle-, hasta el siglo XVI momento de gran expansión urbana en que el sector conoce su integración definitiva en la trama urbana.

El solar donde se realizó la intervención se encuentra junto a la iglesia de Santa Clara, único edificio superviviente del antiguo convento de clarisas instalado en la zona en $1559^{3}$ (Miura Andrades 1995: 347). No poseemos referencias sobre la pertenencia del inmueble que nos ocupa a las propiedades del convento. Tan sólo apuntaremos que el espacio del solar estuvo ocupado en el último siglo por un molino de aceite cuyas infraestructuras habían afectado notablemente a la estratigrafía, quedando las dependencias del convento hacia el este.

\section{II.4. Planteamientos y metodología de la intervención}

Ante la escasa información referente al sustrato arqueológico, debida principalmente al reducido número de actuaciones llevadas a cabo en el sector, se decidió desde la Delegación Provincial de Cultura plantear una intervención en la que se actuase sobre el total de la superficie afectada por los movimientos de tierra. La intervención alternaría el seguimiento del vaciado mecánico del solar con la ejecución de dos pequeños sondeos manuales puntuales a partir de la cota $-2 \mathrm{~m}$ (Fig. 3).

2. Agradecemos al autor su amabilidad al ofrecernos la posibilidad de consultar su tesis de licenciatura inédita.

3. Archivo Municipal de Osuna, Documentos procedentes del Archivo de Rodríguez Marín, Bolsa n 3, Osuna y Puebla de Cazalla, leg. 7, doc. 9 . 


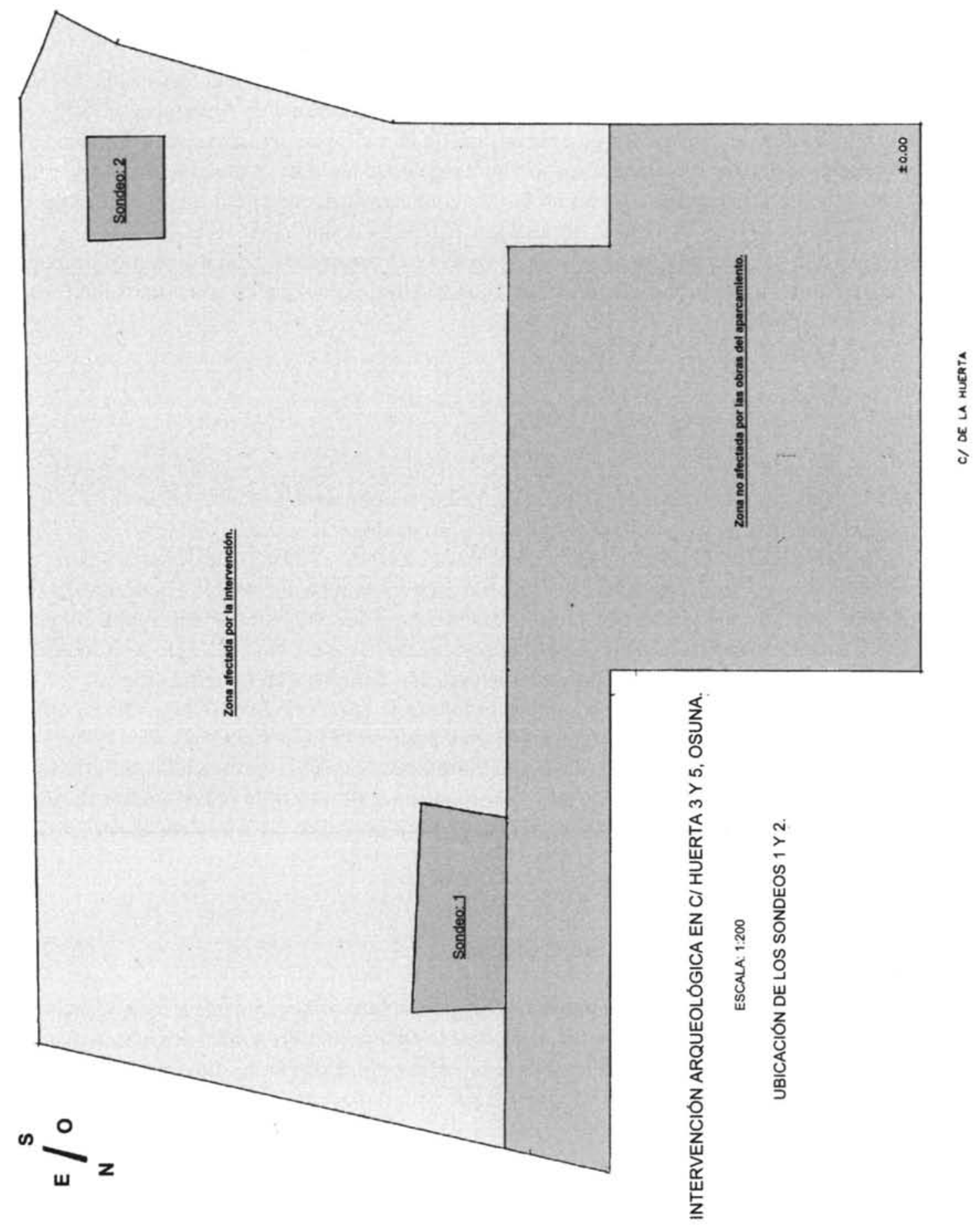


Estos últimos se ubicaron en los extremos del solar, ocupando el Sondeo 1 el extremo norte de la parcela número 3 con un total de $26,5 \mathrm{~m}^{2}$ y el Sondeo 2 el extremo sur de la parcela número 5 ocupando un total de $12 \mathrm{~m}^{2}$. En profundidad los trabajos se desarrollaron hasta -2,70 metros, cota de afección al sustrato según el proyecto de construcción ${ }^{4}$.

\section{II.5. Resultados de la intervención}

Una primera valoración de los resultados obtenidos de la presente actuación ya fue publicada en una revista local (Ruiz Cecilia y Fernández Flores 2000: 181-192) y en el correspondiente volumen del Anuario Arqueológico de Andalucía (Ruiz Cecilia y Fernández Flores 1999b:1041-1053), ahora bien, estimamos de interés realizar aquí un resumen de los mismos con el fin de facilitar la comprensión del contexto en el que se encontró el material numismático objeto de este artículo.

Las primeras actividades antrópicas registradas pueden fecharse, en base al material cerámico y numismático recuperado, en torno a inicios del siglo I a.C. Los restos localizados se reducen a fragmentos de los materiales citados, no documentándose edificaciones, hogares o cualquier tipo de construcción que evidencie una ocupación estable o actividades permanentes. No obstante, el escaso rodamiento de los restos recuperados abre la posibilidad a la existencia de una presencia humana continua en el entorno inmediato. Las actividades desarrolladas en este momento, se llevaron a cabo sobre unos depósitos de origen natural con huellas de sostener vegetación (Fig 4) ${ }^{5}$.

Sobre estos niveles escasamente alterados por el hombre se producirá, en los momentos finales del siglo IV d.C., una ocupación efectiva del enclave. Ésta viene representada por una edificación, realizada básicamente con mampuesto calizo tomado con un mortero extremadamente rico en cal, de la que se documentaron dos muros perpendiculares entre sí que daban lugar a tres espacios diferenciados dentro del corte que denominamos como Estancias 1, 2 y 3 (Fig 5). El edificio se extendía por debajo de la actual iglesia de Santa Clara, documentándose en la intervención el límite sur de la edificación (Fig. 4 y Fig. 5 ) $^{6}$.

Sobre los suelos de las Estancias, realizados con tierra batida, y adosándose a los muros, apareció un nivel de incendio y derrumbe compuesto básicamente por tegulae envueltas en una matriz de cenizas y arcillas que marcan la destrucción y/o abandono de la construcción ${ }^{7}$. A juzgar por la coincidencia entre la cronología de los materiales recuperados en el nivel de abandono y aquellos exhumados en los niveles de uso de la estructura la vida de la edificación fue bastante corta, fechándose ambos momentos en torno finales del siglo IV d.C. o inicios del siglo $\mathrm{V} \mathrm{d}$. C.

4. Todas las cotas aportadas hacen referencia al punto 0'00 de la intervención. Éste coincidía con el nivel de acerado de la calle La Huerta en los límites de las parcelas 5 y 7 ; encontrándose a $+281,20 \mathrm{~m}$ por encima del nivel del mar tomando como referencia la cota de nivel, que a la altura del número 7, aparece en el mapa Esc: 1:500 de Osuna, hoja ${ }^{\circ}$ E-05 1005/21-47 de la Delegación General de Urbanismo perteneciente a la Consejería de Política Terrritorial.

El método de excavación fue el establecido por Edward C. Harris en su libro Principios de Estratigrafía Arqueológica, Ed. Crítica, Barcelona 1991, aunque adaptado a las condiciones particulares de la intervención.

5. El perfil corresponde a la pared norte del Sondeo 1 depósitos corresponden a las unidades estratigráficas $\mathrm{n}^{\circ} 111,108,114$ y 114A).

6. Los muros corresponden a las Unidades 103, 105 y 113 y los suelos a los números 104, 109, 110A representados en las Figuras 4 y 5 .

7. Unidades que forman un mismo depósito pero que individualizamos según la estancia en que aparecieron: 101 en la Estancia 1, 102 en Estancia 2 y 110 en Estancia 3. 


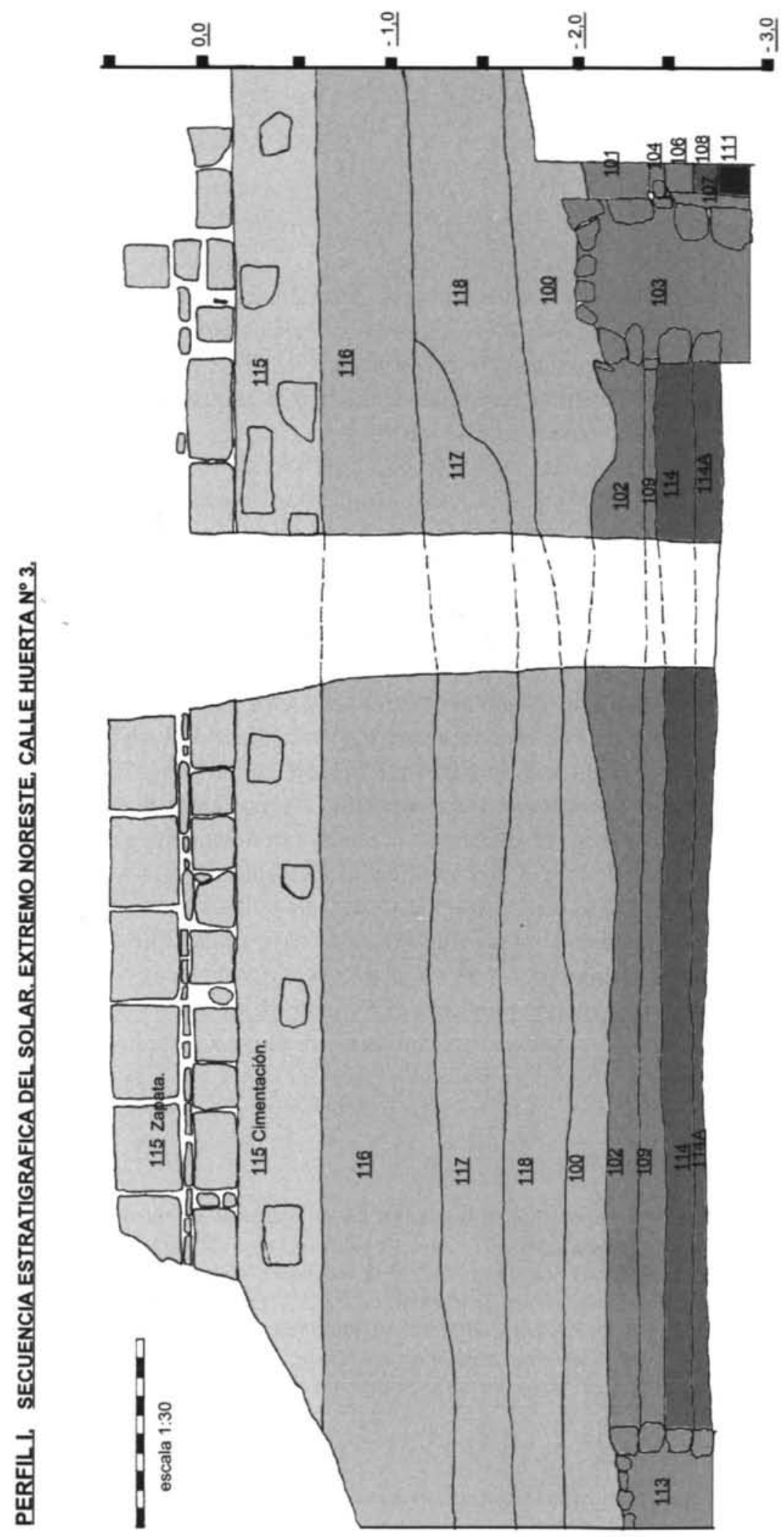

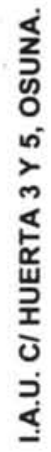

$E$
$\dot{0}$
$\dot{0}$
$\dot{0}$
$\dot{0}$ 

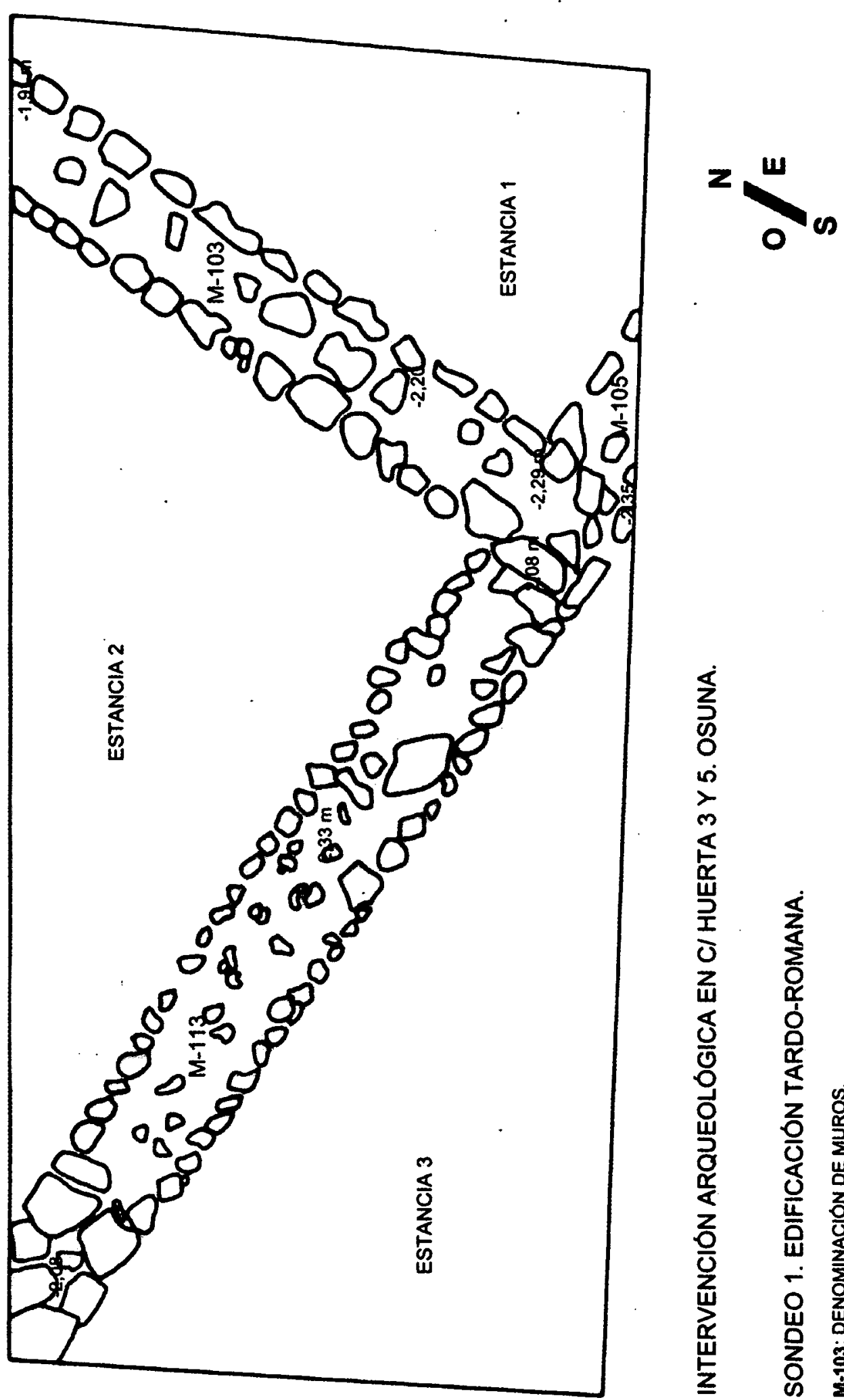
A partir de este momento y hasta los siglos XII-XIII, documentamos un hiato de ocupación y actividad humana. Los niveles correspondientes a estos siglos asientan directamente sobre los estratos de destrucción tardorromanos, encontrándose el límite superior de los mismos decapitado y revuelto. Se inicia en época bajomedieval una etapa de recrecido, que dará como resultado una subida del nivel de $+1,5 \mathrm{~m}$ como mínimo, desde los estratos inferiores fechados en época bajomedieval, hasta los superiores fechados en época moderna ${ }^{8}$.

El carácter de las tierras enmarcadas entre este periodo y el siglo XVIII apuntan a la utilización del espacio como zona de huertas.

A fines del XVIII se instaló sobre el terreno ocupado en la actualidad por las parcelas 3,5 y 7 de la calle la Huerta, un molino de aceite cuya actividad se perpetuó hasta el siglo $\mathrm{XX}^{9}$.

A tenor de los últimos datos aportados por las intervenciones realizadas en el entorno ${ }^{10}$, parece confirmarse con seguridad la presencia humana en el área hacia el siglo I a. C. planteándose la posibilidad de alguna ocupación previa protohistórica ${ }^{11}$. Tras este periodo de ocupación o actividad en el entorno se documenta un hiato en la estratigrafía que abarcaría hasta el siglo IV-V, momento en que constatamos un poblamiento de carácter disperso y marginal representado por las construcciones de calle La Huerta y los materiales de calle Tesoreros. A este momento adscribimos también los elementos constructivos recuperados en Asistente Arjona basándonos en la similitud estratigráfica con el registro de calle La Huerta. A partir de este momento y hasta época bajomedieval no se registra en ninguna de las tres intervenciones (Huerta, Asistente Arjona y Tesoreros) ocupación ni actividad, por lo que suponemos que la zona fue desocupada. Durante la Baja Edad Media el área parece ocuparse intermitentemente y con un carácter marginal, por lo que podemos plantearnos la existencia de un arrabal incipiente con poblamiento disperso. Tras la conquista la zona se desocuparía documentándose en el periodo que va del siglo XIII hasta el siglo XVI una fuerte subida de las cotas del terreno y la probable utilización como zona de huertas del entorno. A partir del siglo XVI el desarrollo de la ciudad extramuros dio lugar a la construcción de amplias casas señoriales que han convivido con molinos, bodegas y huertas hasta mediados del siglo XX.

\section{EL MATERIAL NUMISMÁTICO. CONTEXTO ESTRATIGRÁFICO}

\section{III.1. Localización y recuperación.}

La localización de los materiales objeto de estudio se ha llevado a cabo mediante la prospección electromagnética de las unidades estratigráficas identificadas e individualizadas en el proceso de excavación ${ }^{12}$. En general, se alternó la localización y extracción previa a la excavación, con la localización y extracción

8. Corresponden a este momento los números $100,116,117,118$. El número 115 corresponde a la pared de la sacristía de la iglesia de Santa Clara.

9. Todas las relaciones estratigráficas se pueden observar en el sistema de representación comúnmente utilizado en arqueología denominado Matrix Harris que se adjunta como Figura 6.

10. Destacar los recientes sondeos en calle Tesoreros. A tenor de los resultados podríamos individualizar como zona donde aplicar estas conclusiones al área de ladera que se extendía al oeste de la Puerta del Agua y por debajo de la calle Asistente Arjona (Fernández Flores 2000).

11. Es posible, a partir de la estratigrafía y materiales recuperados en calle Tesoreros que exista un poblamiento previo caracterizado por elementos líticos y cerámicas a mano.

12. El tipo de aparato utilizado fue un detector modelo Beach Comber 4 de la casa White's Electronics con discriminación de objetos de hierro, latón, etc. y compensación automática de la mineralización y salinidad del terreno, con una profundidad de detección para objetos de tamaño normal (moneda de 1 a $3 \mathrm{~cm}$ de diámetro y de 1 a 4 gramos) de $10 \mathrm{~cm}$. Utilizamos detectores de baja potencia con objeto de que la señal emisora nunca traspase la unidad sobre la que estamos trabajando, aun así es necesario prestar siempre atención a este aspecto. 
conforme se retiraba el depósito. En cualquier caso, no se consideró oportuno el uso del detector de metales durante la primera fase de seguimiento de obra con rebaje a máquina, y sí en la realización de los sondeos manuales y la segunda fase del seguimiento y rebaje mecánico, aunque limitándonos a la periferia de la zona ocupada por el Sondeo 1.

Como resultado del barrido del depósito o estructura sobre el que estamos trabajando se registraron una serie de señales cuyo resultado fue la localización y recuperación de los objetos que a continuación contextualizamos.

Se recuperaron un total de 11 monedas y 6 objetos metálicos de cierta relevancia, además de numerosos restos y fragmentos de carácter variado.

Siete de las monedas y la inmensa mayoría de los objetos de metal fueron recuperados en los $26,5 \mathrm{~m}^{2}$ que ocupó el Sondeo 1, ya que éste se excavó manualmente y se prospectó de forma intensiva con el detector de metales. Las otras tres piezas y los restantes objetos de metal se recuperaron en la zona inmediata al sondeo.

\section{III.2. Contexto estratigráfico de las piezas}

\section{III.2.A. Material recuperado en los niveles de origen natural alterados en torno al siglo I a.C.}

En los depósitos que formaban la base de la estratigrafía se recuperaron dos piezas, identificadas como un as de Ilipa Magna (Alcalá del Río) y un semis republicano de imitación, fechables en torno al siglo I a.C.

El conjunto de niveles o unidades estratigráficas adscribibles a este momento (Figura 3. Unidades 108, $111,114,114 \mathrm{~A}$ y 112) pueden considerarse parte de una formación sedimentaria de origen natural que presentaba en su superficie una leve alteración provocada por la presencia humana ${ }^{13}$. Por tanto, todos los paquetes de tierra que formaban la base de la estratigrafía presentaban características similares ${ }^{14} \mathrm{con} \mathrm{la}$ salvedad de que en los niveles superiores los restos arqueológicos comienzan a estar presentes, disminuyendo su proporción conforme bajamos de cota.

La cronología señalada para la alteración de los depósitos superficiales (siglo I a.C.) y por tanto para la presencia humana en el entorno, viene dada por el as de Ilipa localizado en la unidad 112 y por el semis republicano de imitación hispana hallado en la unidad 108, contrastándose esta cronología con la aportada por los fragmentos de bordes y galbos de cerámica pintada a bandas de tradición turdetana que se recuperaron junto al as y por un fragmento de cerámica campaniense, acompañado asimismo de cerámica pintada de tradición indígena, aparecidos junto al semis.

El escaso desgaste de los materiales recuperados nos llevó a plantear la existencia de un poblamiento muy cercano, probablemente en una zona más elevada (noreste o noroeste). A partir de este posible núcleo de población, se produciría el rodamiento y transporte de los restos materiales localizados.

13. La profundidad máxima alcanzada estuvo en $-2,94$ m por debajo del nivel del acerado de calle La Huerta. Los depósitos incluidos en esta fase alcanzaban como cota superior los $-2,50 \mathrm{~m}$. La antropización se registra a partir de $-2,78 \mathrm{~m}$.

14. El depósito de base (Figura 3 unidad: 111) presentaba una textura limo-arcillosa, color castaño claro, una alta homogeneidad y cierto grado de edafización (presencia de poros y gasterópodos). Sobre este nivel diferenciamos un estrato formado por las unidades 108 (Estancia: 1), 114 (Est. 2) y 112 (Est. 3), de características similares a 111 en cuanto a matriz, grado de edafización, y contenido natural, pero que muestran contenido antrópico. 


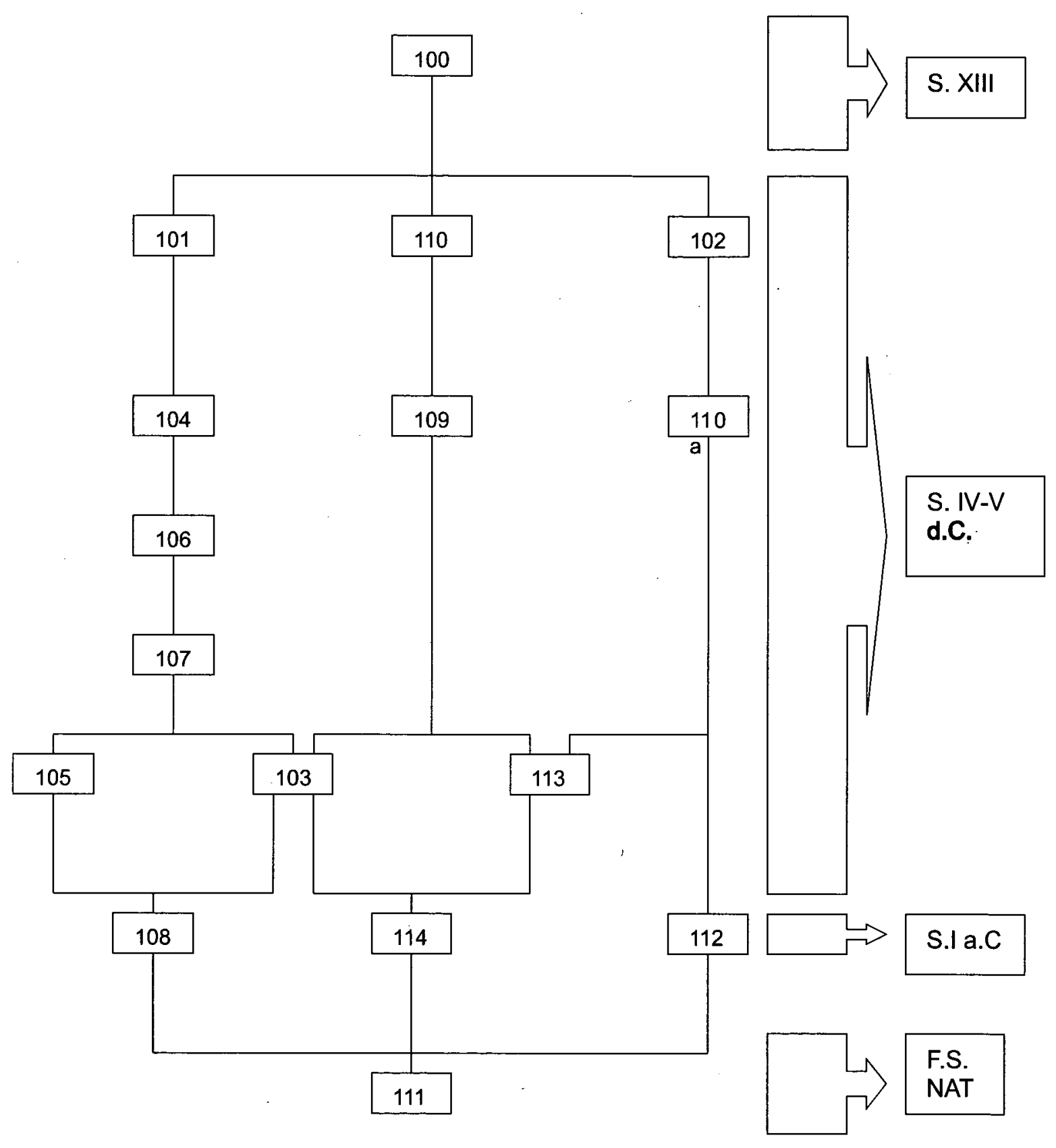

Fig. 6. Relaciones estratigráficas representadas en forma de matrix Harris 
III.2.B. Material recuperado en los niveles de uso de la edificación tardorromana. Fines Siglo IVd. C.-Inicios Siglo V d.C.

En los momentos finales del siglo IV se documenta la ocupación del solar por el hombre. Sobre los depósitos descritos anteriormente se levanta una edificación realizada en mampostería de la que se exhumó el límite sur. En los suelos de tierra apisonada correspondientes a la construcción, se recuperaron un total de 3 monedas de bronce correspondientes a los emperadores Delmacio, Teodosio y Arcadio.

Los restos exhumados se reducían a dos muros perpendiculares entre sí que daban lugar, dentro del corte, a tres espacios que denominamos como Estancias 1,2 y $3^{15}$. Los suelos correspondientes a la edificación se disponían directamente sobre los niveles del siglo I a.C. presentando una compactación notable y superficie nivelada ${ }^{16}$.

Las monedas se recuperaron en las soleras de las Estancias 2 y 3 (Figura 5). Dentro de la primera se recuperó un AE2 de Arcadio acuñado en Antioquía y dentro de la segunda, un AE2 acuñado bajo Teodosio en Constantinópolis y un AE3/4 acuñado por Delmacio en Arelate. En principio, la cronología de acuñación del material numismático fecharía la edificación o al menos el único nivel de uso, en la ultima década del siglo IV; no obstante, debido al amplio periodo de circulación de estos tipos numismáticos, es preciso contrastar la datación de las monedas con la cronología que aporte el material cerámico que acompañaba a las piezas. Éste se caracteriza por una mayor proporción de cerámicas de uso doméstico, muchas de ellas con restos de ceniza, y la presencia de cerámica sigillata africana. La cronología ofrecida por los materiales cerámicos situaba el expediente constructivo a fines del siglo IV.

\section{III.2.C. Material numismático recuperado en los niveles de destrucción de la edificación}

Sobre los suelos de la edificación descrita en el apartado anterior se documentó un nivel de incendio y destrucción caracterizado por la presencia de cenizas, carbones y tegulae revueltas que llegaba a alcanzar los 35-40.cm de potencia ${ }^{17}$. En la Estancia 1 y dentro de este nivel, se recuperaron tres pequeñas monedas de bronce y múltiples objetos de metal. Las piezas numismáticas correspondían a un AE2 de Teodosio acuñado en Cyzicus (en la actual Turquía) y un AE2 de Magno Máximo acuñado probablemente en Lugdunum, resultando ilegible la última de las monedas.

Dentro del nivel de incendio y destrucción, se podía distinguir una capa inferior discontinua y de escasa potencia, compuesta por cenizas y carbones mezclados con restos de arcilla rojiza, y una capa superior formada básicamente por un revuelto de tegulae mezcladas con cenizas, carbones y arcillas. Algunos de estos elementos constructivos asentaban horizontalmente sobre el nivel anterior y en otras ocasiones directamente sobre el suelo de las estancias.

En esta zona de contacto, se recuperaron la mayoría de los materiales metálicos y cerámicos correspondientes al depósito de destrucción. Además de las monedas, entre los primeros cabría destacar la aparición de una fíbula, un cazo de mango largo, fragmentos de láminas de cobre, restos de plomo fundido, clavos de hierro y otros objetos del mismo metal pero de funcionalidad imprecisa.

15. En adelante Est. 1, Est. 2 y Est. 3.

16. Al dar lugar la edificación exhumada a tres espacios diferentes (denominadas como Estancias 1,2 y 3 ) los niveles de uso correspondientes se numeraron de forma distinta ya que no presentaban contacto físico entre ellos aunque sus características eran idénticas. (U.E.104 en Est.1, U.E. 109 en Est.2 y U.E. 110a en Est. 3).

17. Denominamos a estos niveles como U.E.101 en Est.1, U.E. 102 en Est. 2 y U.E.110 en Est. 3. 
Entre el revuelto de tegulae se recuperaron algunos fragmentos de placas de mármol, un ladrillo en relieve tardorromano (Marín Gómez 1982: 37-43), mampuestos y algunos ímbrices, además de un aplique ornamental en bronce con forma de rostro femenino (Oria Segura en prensa).

Tanto el nivel descrito como la edificación tardorromana fueron decapitados en época bajomedieval o moderna como consecuencia de la dedicación de los terrenos del solar a huertas.

En cuanto a la fecha de destrucción de la edificación la fecha de acuñación de las monedas nos sitúa de nuevo en la última década del siglo IV. No obstante, al igual que señalamos en el apartado anterior, se hace necesario contrastar esta cronología con la que puede aportar el material cerámico y latericio. En este caso, las cronologías aportadas por los materiales recuperados en los distintos ámbitos coinciden en fechar el depósito de incendio y destrucción en torno a fines del siglo IV d. C. o inicios del V.

\section{III.2.D. Monedas recuperas durante el rebaje mecánico}

Tras dar por finalizada la intervención manual, se procedió al rebaje de las zonas próximas al Sondeo 1. En el área no se localizaron nuevas estructuras ya que la construcción se extendía sólo hacia el norte bajo la iglesia de Santa Clara. Por otro lado, la pendiente de los estratos hacia el sur hizo que los depósitos tardorromanos quedasen por debajo de las cotas de afección de garaje por lo que sólo se documentaron en las zonas inmediatas a la construcción.

Se localizaron en el área de ampliación de la Estancia 3 dos monedas en mal estado de conservación. Se trata de un AE2 acuñado en el último cuarto del siglo IV pero ilegible y un cententional de imitación correspondiente a Magnencio o Decencio con ceca ilegible.

\section{CATÁLOGO DEL MATERIAL NUMISMÁTICO}

Hemos distribuido las monedas según su contexto arqueológico en cuatro grupos, coincidentes con las agrupaciones ya señaladas en el apartado anterior. Dentro de un conjunto cada moneda es descrita y estudiada en una ficha independiente. Para facilitar el manejo de los datos en el presente artículo, identificamos cada pieza con un número junto a su denominación, emisor (emperador, ciudad, rey etc.), ceca (lugar de acuñación) y cronología. A continuación se ofrece, en el apartado "Identificación", el yacimiento al que pertenece la pieza, la sigla del museo, la unidad de intervención o corte en que ha sido localizada, su unidad estratigráfica y el número de inventario que se le ha adjudicado en la intervención.

En el apartado siguiente, "Descripción”, se realiza una descripción detallada de los tipos, leyendas (las zonas no legibles aparecen entre paréntesis con puntos suspensivos y las dudosas entre paréntesis), marcas o resellos presentes en la moneda, ocupándonos en primer lugar del anverso y a continuación del reverso.

Tras los aspectos formales señalamos los caracteres físicos: en primer lugar, el peso expresado en gramos, a continuación, el módulo o diámetro en milímetros, el grosor también en milímetros, el tipo de metal en que se realiza la pieza y por último, el eje o ejes es decir la relación entre el eje del tipo de anverso y de reverso. Como es habitual, hemos colocado el eje de tipo de anverso a las 12 horas y señalado la posición que ocupa el eje del tipo de reverso en la esfera del reloj.

Por último se ofrece un paralelo bibliográfico. Las abreviaturas presentes responden a las siguientes obras: 
Calicó = VV.AA., Numismática Española. 1474-1994. Catálogo de todas las monedas emitidas desde los Reyes Católicos hasta Juan Carlos I, Barcelona, 1994.

Marcos = MARCOS ALONSO, C., "Aportación a la circulación de las imitaciones de divisores romanorepublicanos en la península Ibérica”, Numisma, n² 237, Ene-Jun 1996, pp. 199-223.

R.I.C. = VV.AA., Roman Imperial Coinage, vols. VII, VIII y IX, London, 1966, 1981, 1972.

Sáez y Blanco = SÁEZ BOLAÑO, J. A. y BLANCO VILLERO, J. M., Las Monedas de la Bética Romana, vol. II (conventus Hispalensis), San Fernando, 2001.

VV.AA. = VV.AA., Historia Monetaria de Hispania Antigua, Madrid, 1998.

Villaronga = VILLARONGA, L., Corupus Nummum Hispaniae ante Augusti Aetatem, Madrid, 1994.

Vives = VIVES Y ESCUDERO, A, La Moneda Hispánica, 2 tomos, Madrid, 1926 (reedición 1980).

\section{1. Material numismático localizado en los niveles naturales alterados en el siglo I a.C.}
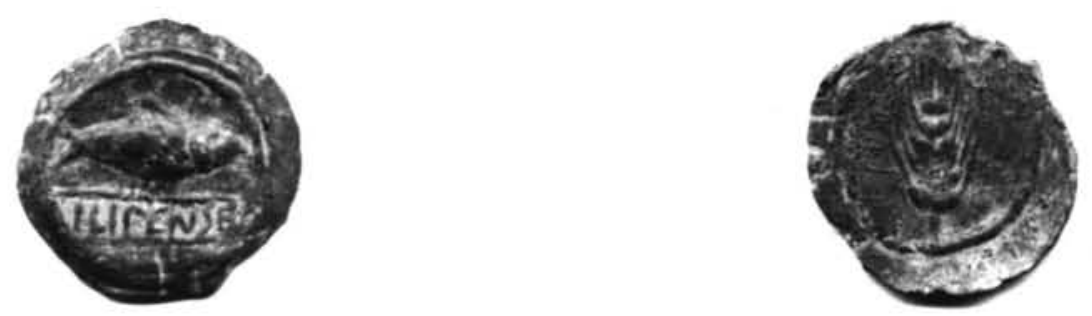

PIEZA Nº: AS. ILIPA MAGNA (ALCALÁ DEL RÍO, SEVILLA). ILIPA. SIGLO I A. C.

Identificación:

Unidad de intervención: Sondeo 1. Unidad Estratigráfica: 112 Sigla Museo: ROD/99-14/112-1

\section{Descripción:}

Anverso: Sábalo a derecha, debajo epígrafe entre líneas: ILIPENSE.

Reverso: Espiga de trigo.

Peso: 13,4 gr.Diámetro: $29 \mathrm{~mm}$. Grosor: $3,7 \mathrm{~mm}$. Metal: Bronce Ejes: 5

Referencias: Vives, lámina CVII, $\mathrm{n}^{\circ} 4$.

Villaronga, Ilipense tipo 7, pág. 375 (Villaronga lo clasifica como un semis).

Sáez y Blanco, tipo $13^{\mathrm{a}}$, pág. 105. 

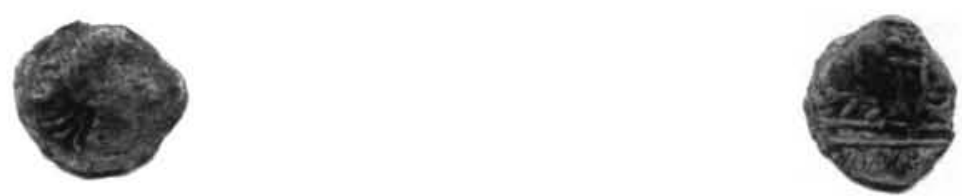

PIEZA $N^{\circ}$ 2: SEMIS REPUBLICANO ANÓNIMO, IMITACIÓN HISPANA. MEDIADOS SIGLO I A. C. Identificación:

Unidad de intervención: Sondeo 1. Unidad Estratigráfica: 108 Sigla Museo: ROD/99-14/108-1

\section{Descripción:}

Anverso: Cabeza varonil a derecha probablemente Saturno, marca $S$ detrás de la cabeza.

Reverso: Proa de barco a izq. En el exergo leyenda retrograda AMO( $\mathbf{R})$.

Peso: 2,0 gr. Diámetro: 17,6 mm. Grosor: 1,7 mm. Metal: Cobre Ejes: 9

Referencias: VV.AA., pág. 342, fig 260. Variante.

Marcos, tipos 1-6, pág. 212. Variante de peso reducido.

IV.2. Material numismático localizado en los niveles de suelo de la edificación tardorromana. Última década del siglo IV/siglo $\mathrm{V}$
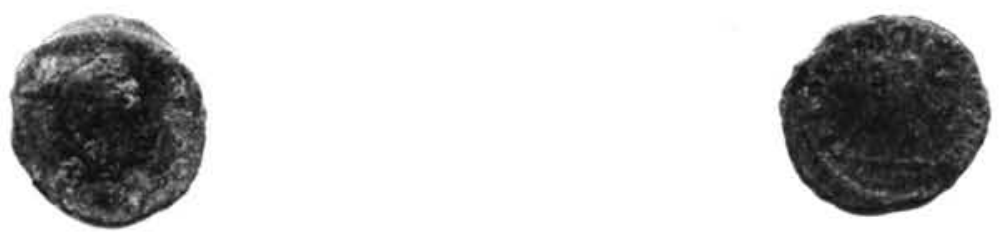

PIEZA Noª: AE2. ARCADIO. ANTIOQUÍA. 392-395 D. C.

Identificación:

Unidad de intervención: Sondeo 1.Unidad Estratigráfica: 109 Sigla Museo: ROD/99-14/109-1

\section{Descripción:}

Anverso: Busto de Arcadio diademado a derecha. Alrededor leyenda partida por el busto: (...AD)I-US PF AUC.

Reverso: Emperador de frente en pie con cabeza a la derecha portando estandarte y globo. En el exergo marca de ceca: ANT(B). Alrededor leyenda: GLORIA-ROMANORUM

Peso: 4,2 gr. Diámetro: $21,5 \mathrm{~mm}$. Grosor: $1,8 \mathrm{~mm}$. Metal: Cobre Ejes: 5

Referencias: R.I.C. Vol IX pág. 294 Antioquía 68d/1 o 68d/2. Queda dudosa la letra correspondiente a la oficina (B o G). 

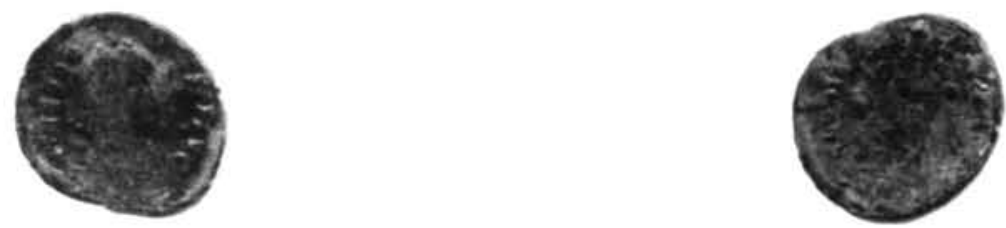

PIEZA N4: AE2. TEODOSIO. CONSTANTINÓPOLIS. 392-395 D. C.

Identificación:

Unidad de intervención: Sondeo 1. Unidad Estratigráfica: 110 Sigla Museo: ROD/99-14/110-1

Descripción:

Anverso: Busto de Teodosio diademado a derecha. Alrededor leyenda partida por el busto: DN THEODO-SIUS PF AUC.

Reverso: Emperador de frente en pie con cabeza a la derecha portando estandarte y globo. En el exergo marca de ceca: CONSA. Alrededor leyenda: GLORIA-ROMANORUM

Peso: 3,3, gr. Diámetro: $23,15 \mathrm{~mm}$. Grosor: $1,5 \mathrm{~mm}$. Metal: Cobre Ejes: 6

Referencias: R.I.C. Vol IX pág. 235 Cons 88 a/1.
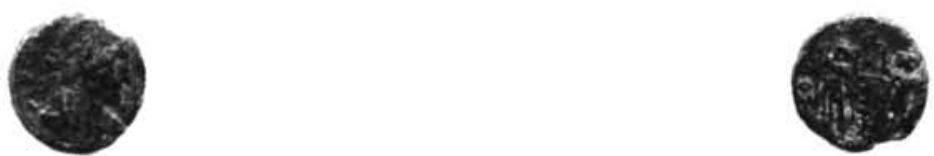

PIEZA N ${ }^{\circ}$ : FOLLIS. DELMACIO. ARLES. 335-337 D C.

Identificación:

Unidad de intervención: Sondeo 1. Unidad Estratigráfica: 110 Sigla Museo: ROD/99-14/110-2

Descripción:

Anverso: Busto de Delmacio diademado a derecha. Alrededor leyenda: FL DELMA(...).

Reverso: Dos soldados en pie con escudos y lanzas. Entre ellos estandarte con círculo en campo. En el exergo marca de ceca: (P)CO(...). Alrededor leyenda: GLOR-IAEXER(...).

Peso: 1,4 gr. Diámetro: $14 \mathrm{~mm}$. Grosor: $1,4 \mathrm{~mm}$. Metal: Cobre Ejes: 7

Referencias: R.I.C. Vol. VII pág. 277 Arles. Dudas entre los números 398/399/406. Variante en círculo. 
IV.3 Material numismático localizado en los niveles de destrucción de la edificación tardorromana. Última década del siglo IV/siglo $\mathrm{V}$ d.C.
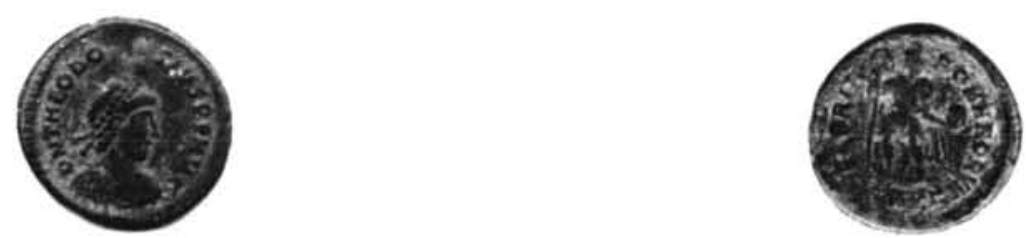

PIEZA N 6 : AE2. TEODOSIO. CYZICUS. 392-395 D. C.

Identificación:

Unidad de intervención: Sondeo 1. Unidad Estratigráfica: 101 Sigla Museo: ROD/99-14/101-1

Descripción:

Anverso: Busto de Teodosio diademado a derecha. Alrededor leyenda partida por el busto: DN THEODO-SIUS PF AUC.

Reverso: Emperador de frente en pie con cabeza a la derecha portando estandarte y globo. En el exergo marca de ceca: SMKГ. Alrededor leyenda: GLORIA-ROMANORUM

Peso: 5,3, gr. Diámetro: $22 \mathrm{~mm}$. Grosor: $2 \mathrm{~mm}$. Metal: Cobre Ejes: 12

Referencias: R.I.C. Vol. IX pág. 246 Cons. 27 (a)/3.
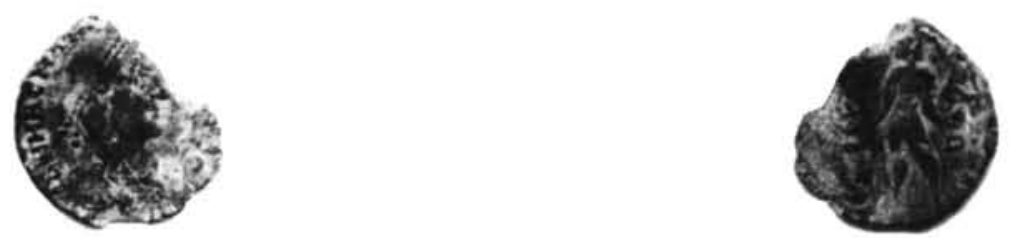

PIEZA N%: AE2. MAGNO MÁXIMO. 383-388 D. C. CECA GALA ( ¿LUGDUNUM? ).

Identificación:

Unidad de intervención: Sondeo 1. Unidad Estratigráfica: 101 Sigla Museo: ROD/99-14/101-2

Descripción:

Anverso: Busto de Magno Máximo diademado a derecha. Alrededor leyenda: DN MAG MAX(...)C.

Reverso: Emperador en pie portando Victoria y levantando personaje arrodillado. Alrededor leyenda: (...)R(...). Marca de ceca fuera de cospel, en el campo marca de oficina $\mathbf{P}$ a izquierda de tipo.

Peso: 3,7 gr. Diámetro: $22 \mathrm{~mm}$. Grosor: $1,7 \mathrm{~mm}$. Metal: Cobre Ejes: 12

Referencias: R.I.C. Vol IX pág. 49 N 32/3 o 32/4. 

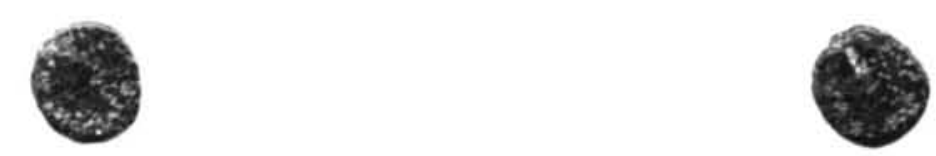

PIEZA No8: AE4. Ilegible.

Identificación:

Unidad de intervención: Sondeo 1. Unidad Estratigráfica: 101 Sigla Museo: ROD/99-14/101-3

Descripción:

Anverso: Ilegible.

Reverso: Ilegible.

Peso: 1,3 gr. Diámetro: $12,4 \mathrm{~mm}$. Grosor: $1,7 \mathrm{~mm}$. Metal: Cobre

Referencias: Sin referencias.

IV.4. Material numismático localizado durante el movimiento de tierras en torno a la Estancia 3.
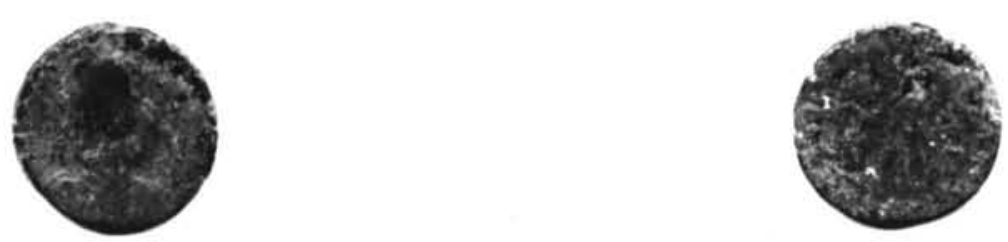

\section{PIEZA $N^{\circ}$. AE2. ILEGIBLE. CECA ILEGIBLE. $2^{a}$ MITAD SIGLO IV D. C.}

Identificación:

Unidad de intervención: Movimiento tierras. Unidad Estratigráfica: MT Sigla Museo: ROD/99-14/MT/1

\section{Descripción:}

Anverso: Busto a derecha. Alrededor leyenda ilegible.

Reverso: Emperador en pie portando Victoria y levantando personaje arrodillado. Alrededor leyenda: REP(...). Marca de ceca ilegible.

Peso: 4,1 gr. Diámetro: 21,4 mm. Grosor: 1,5 mm. Metal: Cobre Ejes: 12

Referencias: Sin referencias. 

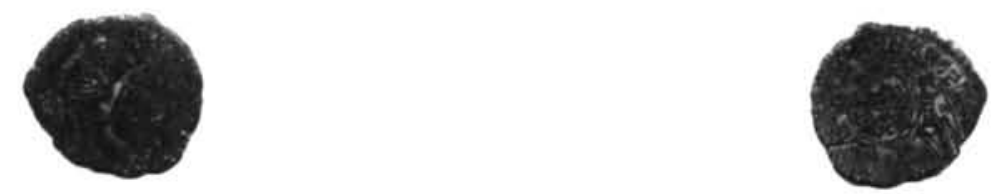

PIEZA N ${ }^{\circ}$ 10: AE3?. MAGNENCIO O DECENCIO. PROBABLE IMITACIÓN BARBARA. CECA GALA (¿TRIERS, AMIENS, LYONS?). 350-353 D. C.

Identificación:

Unidad de intervención: Movimiento tierras. Unidad Estratigráfica: MT Sigla Museo: ROD/99-14/MT/2.

\section{Descripción:}

Anverso: Busto a derecha. Alrededor leyenda ilegible.

Reverso: Victorias portando escudo con inscripción VOT/MULT/X. Alrededor leyenda: (...)NAUCET CA(...). Marca de ceca fuera de cospel.

Peso: 1,9 gr. Diámetro: $18 \mathrm{~mm}$. Grosor: $1,3 \mathrm{~mm}$. Metal: Cobre Ejes: 12

Referencias: R.I.C. VOL VIII.
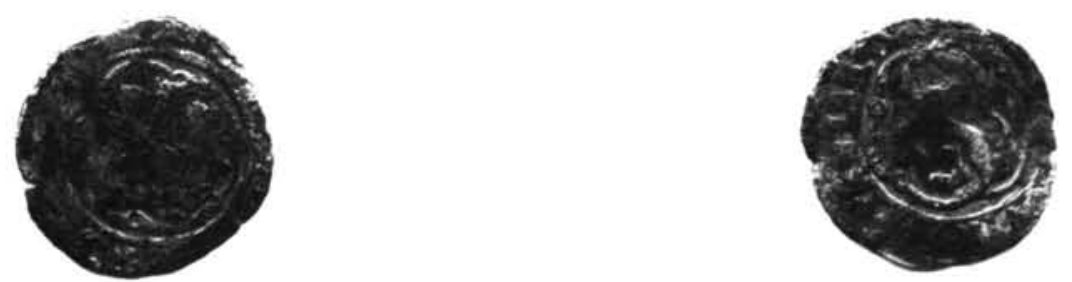

PIEZA N ${ }^{\circ} 11$ : CUATRO MARAVEDÍES. CARLOS I. SANTO DOMINGO. 1516-1556 D. C.

Identificación:

Unidad de intervención: Movimiento tierras. Unidad Estratigráfica: MT Sigla Museo: ROD/99-14/MT/3

Descripción:

Anverso: Castillo en orla polilobulada inserta en gráfila circular. Alrededor leyenda ilegible. A dr. de castilo $\mathbf{S}$ a izq. $\mathbf{P}$.

Reverso: León en orla polilobulada inserta en gráfila circular. Bajo león $\mathbf{F}$. Alrededor leyenda: (...)INDIAR(...).

Peso: 4,6 gr. Diámetro: 22,5 mm.Grosor: 1,2 mm. Metal: Vellón Ejes: 9

Referencias: Calicó, pág. 132, tipo 58, $\mathrm{n}^{\circ} 163$. 


\section{ANÁLISIS ESTADÍSTICO}

\section{V.1. Estado de conservación del material}

Datos: Número total de piezas localizadas durante la intervención (Piezas 1 a 11).

Categorías: Se han establecido tres categorías correspondientes a otros tantos grados de conservación -Identificables, no identificables y dudosas-.

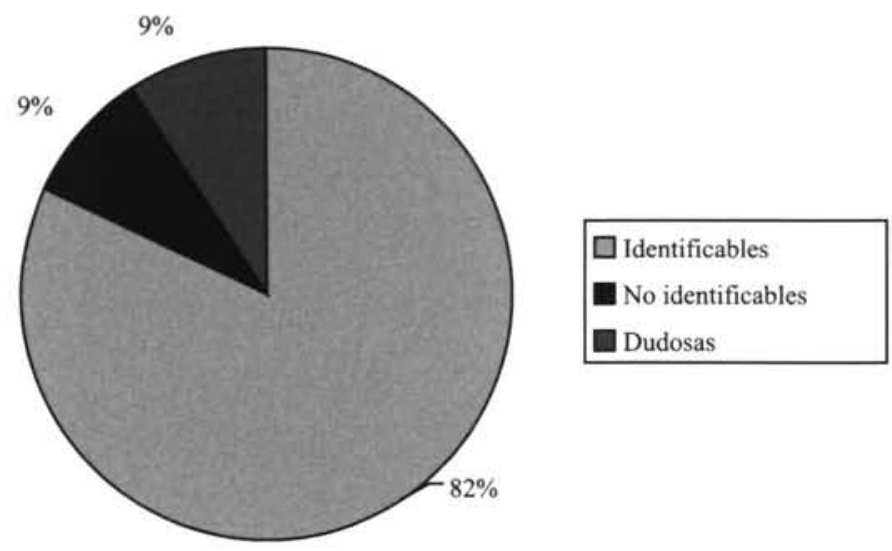

\section{V.2. Secuencia ocupacional del solar e intensidad de ocupación según el material numismático}

En este apartado se establece la horquilla de ocupación del solar a partir del material numismático recuperado dentro de cada periodo histórico convencional.

Nos acercamos a la intensidad de ocupación teniendo en cuenta el número de monedas encuadrables en cada periodo histórico dentro de la secuencia general de ocupación del solar.

Población: Total de piezas identificables y dudosas recuperadas en la intervención 10 (Piezas 1 a 11, excepto Pieza 8). 


\section{V.2.A. Periodos históricos y número de monedas por periodo}

$\mathrm{N}^{\mathrm{o}}$ de monedas por periodos históricos
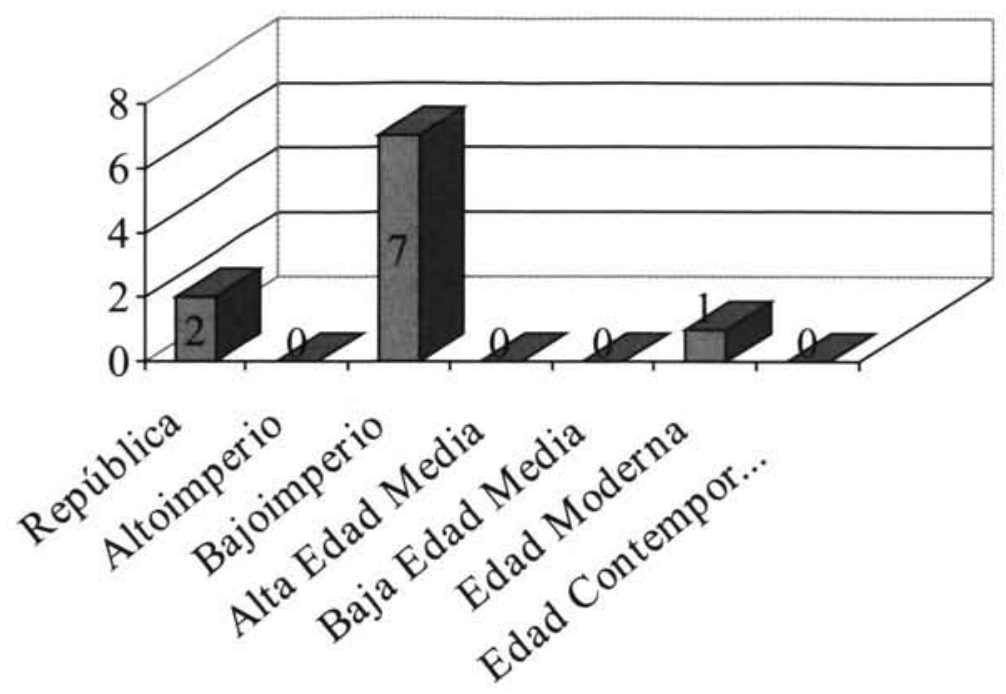

V.2.B. Curva diacrónica y de intensidad de ocupación según el material numismático
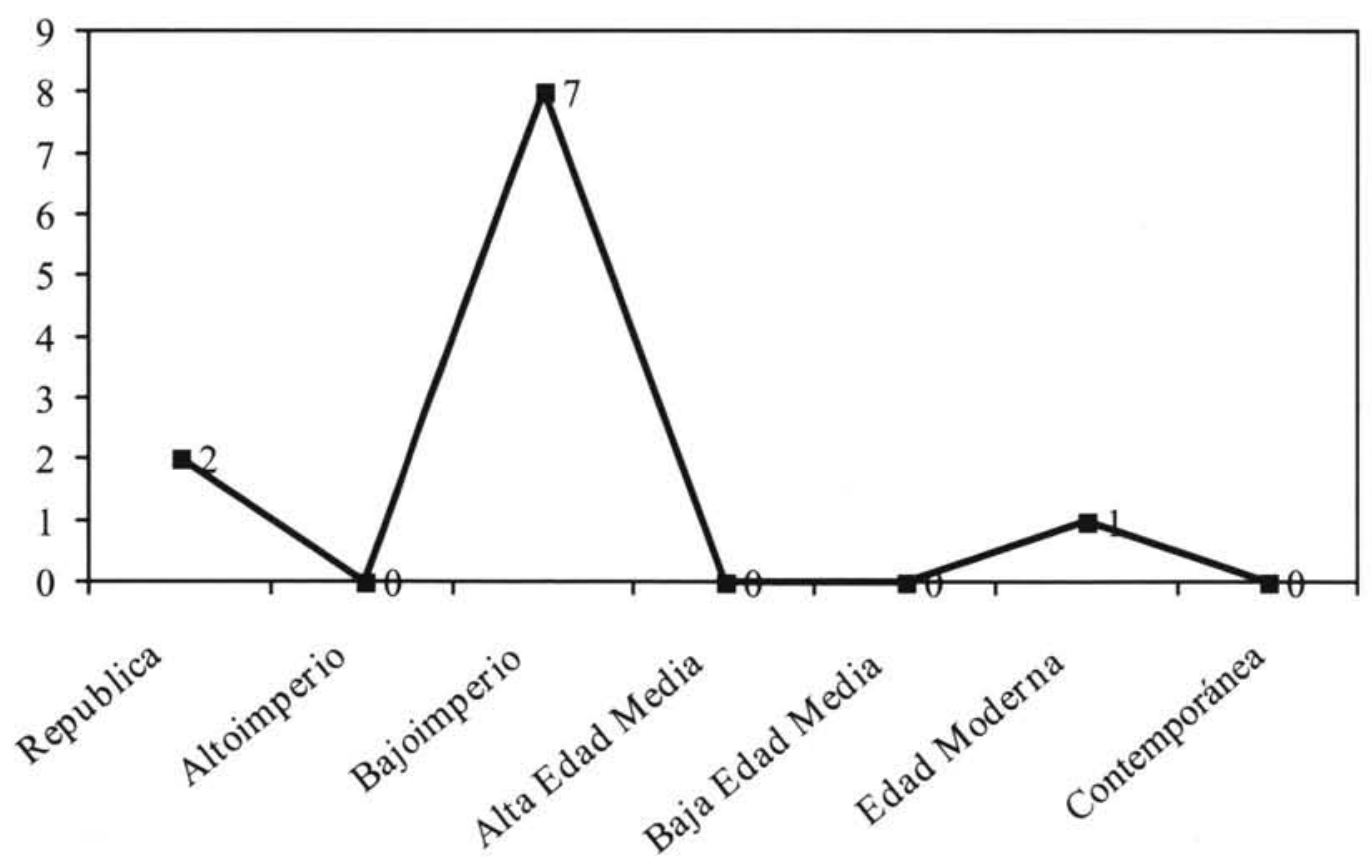


\section{V.2.C. Discusión}

La secuencia ocupacional e intensidad de ocupación resultantes del análisis del material numismático muestran una correspondencia bastante aproximada con la secuencia e intensidad registradas durante en la intervención arqueológica, sobre todo si tenemos en cuenta que la anulación de los depósitos de época moderna y contemporánea se realizó por medios mecánicos y sin realizar prospecciones electromagnéticas. Este hecho explica la ausencia completa de material en época Contemporánea y la escasez de moneda Edad Moderna y Medieval.

Podemos confirmar una primera actividad humana en torno al siglo I a.C.; tras la cual se produce una ocupación efectiva del enclave fechada en el tránsito del siglo IV al V. La edificación que representa esta ocupación se destruye de forma violenta poco después, quizás en relación con las invasiones de principios del siglo V. A partir de este momento y hasta los siglos XII-XIII, se registra un hiato ocupacional que se refleja en la ausencia de material numismático. El periodo de utilización del solar como zona de huertas (periodo bajomedieval y moderno -excepto $\mathrm{s}$. XVIII-), queda reflejado sólo a través de una pieza correspondiente al siglo XVI, explicándose este hecho tanto por el carácter de las actividades agrícolas como por la excavación por medios mecánicos de los depósitos correspondientes a este periodo. La ocupación y urbanización definitivas del solar a partir del XVIII no quedará documentada a través del material numismático por este último motivo.

\section{V.3. Emisores presentes}

Se muestra a continuación en un diagrama de barras la totalidad de emisores presentes y el número de piezas correspondientes a cada uno de ellos.

Población: Piezas con emisor identificado. Total 8 monedas (Piezas $N^{\circ} 1,2,3,4,5,6,7$ y 11).

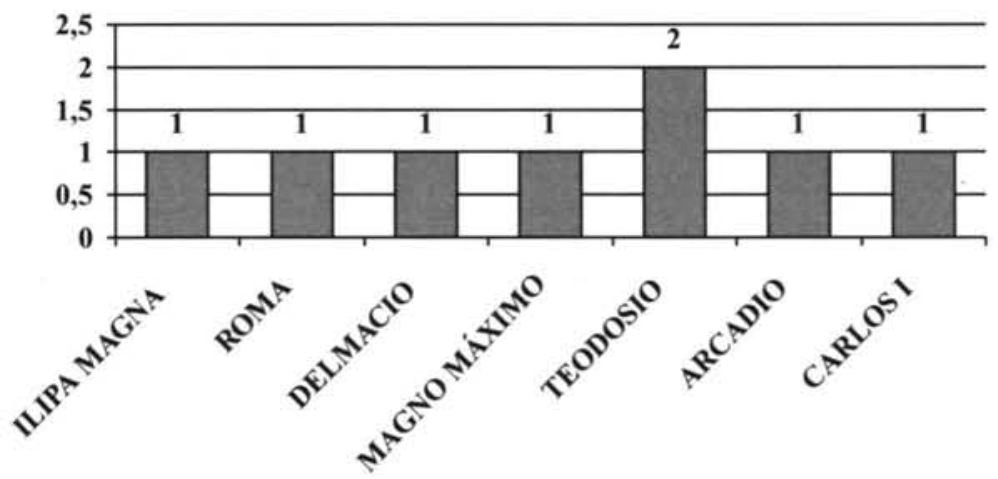

Los emisores más representados son aquellos correspondientes al periodo bajoimperial, destacando entre éstos Teodosio con dos numismas. Como se puede comprobar, las cronologías correspondientes a Magno Máximo, Teodosio y Arcadio encuadran la ocupación y abandono del solar en un periodo bastante concreto, comprendiéndose la fecha de acuñación de cuatro de las cinco piezas de este momento entre el 383-395 d.C. La excepción la marca la moneda de Delmacio (335-337 d.C.), que estaría circulando de forma residual, puesto que en el mismo estrato se recuperó una de las piezas correspondientes a Teodosio. 
En cuanto a los emisores correspondientes a la fase de presencia humana en el entorno en época romanorepublicana, las cronologías que actualmente se manejan para las monedas adscribibles a este momento sitúan éstas dentro del siglo I a.C. Como emisor del semis romano-republicano de imitación hispana, hemos optado por poner Roma, en tanto que el carácter de estas acuñaciones podía ser oficioso (Arévalo y Campo 1998: 318-325). En la actividad emisora de la ciudad de Ilipa Magna (Alcalá del Río) esta acuñación se sitúa en el último periodo de emisiones de los tres reconocidos por el momento (Chaves Tristán 1998: 270-272).

La moneda de Carlos I resulta llamativa ya que se trata de una emisión bastante escasa y acuñada en las Indias Occidentales.

\section{V.4. Emisores por fases de ocupación}

Teniendo en cuenta que son las primeras fases de la secuencia estratigráfica las mejor representadas y las que pueden ofrecer una información más representativa del circulante monetario, realizamos un acercamiento a los emisores presentes en los niveles correspondientes a los tres primeros periodos cronoculturales establecidos en la intervención.

Población: Monedas recuperadas con emisor identificado encuadrables en las tres primeras fases de la periodización (presencia humana en el entorno en época romano-republicana, primera ocupación efectiva en época tardoimperial y destrucción de la edificación bajoimperial anterior). $\mathrm{N}^{\circ}$ piezas: 7 (Piezas $\mathrm{N}^{\circ} 1$, $2,3,4,5,6$ y 7$)$.
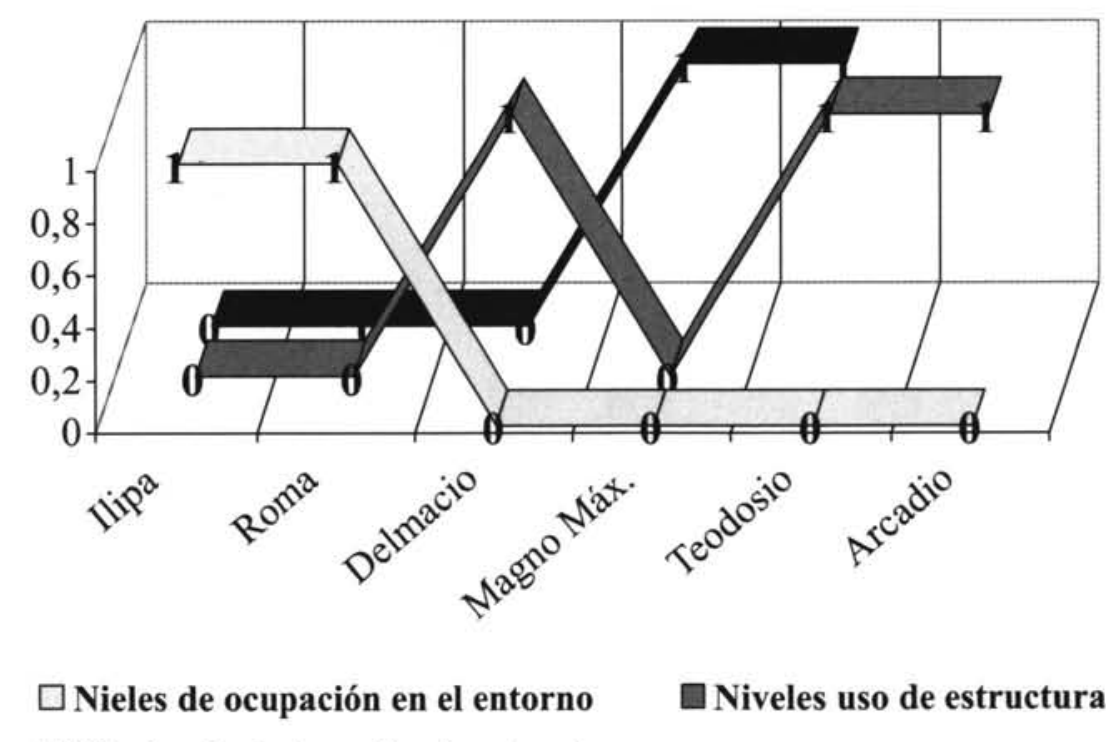

\section{Niveles uso de estructura}

- Niveles de destrucción de estructura

El gráfico refleja la correspondencia entre los emisores y las fases establecidas en la intervención así como la cercanía cronológica entre las fases de ocupación y destrucción-abandono.

La ordenación por emperadores podría dar lugar a confusión ya que en los niveles de uso de la edificación bajoimperial se encuentran piezas de Arcadio, mientras en los niveles de destrucción de la misma las monedas 
más antiguas sólo llegan a Teodosio, emperador previo al anterior. No obstante, tenemos que tener en cuenta que la presencia de una pieza de Arcadio en los niveles de uso no indica ninguna irregularidad, aunque su acceso al imperio sea posterior a Teodosio, puesto que la fecha de acuñación de las monedas atribuibles a ambos coincide (392-395 d. C.), debido a las emisiones realizadas por Arcadio bajo el título de Augusto antes de la muerte de Teodosio, su padre.

Aparte de este aspecto resulta interesante constatar esta pequeña representación del circulante en los tres momentos seleccionados. La convivencia de las monedas de Ilipa Magna y el semis republicano de imitación, la convivencia en los niveles de uso de la estructura de la pieza de Delmacio junto a la pieza de Teodosio y Arcadio, y por último la convivencia de las monedas de Magno Máximo y Teodosio.

La pervivencia constatada (Marot 1999: 415-422; Marot y Llorens 1995: 253-261) de este último numerario durante gran parte del siglo V y VI quizá pueda explicar la coincidencia de fechas entre los niveles de uso de la estructura bajoimperial y sus niveles de destrucción, planteándose esta hipótesis como complementaria a la explicación que antes apuntamos de una destrucción del enclave poco después de su construcción. En cualquier caso el material cerámico tampoco apunta hacia un lapsus de tiempo demasiado prolongado entre la construcción y destrucción de la edificación aportando la fecha más tardía un fragmento de ladrillo decorado en relieve (Martín Gómez 1982: 37-43).

\section{V.5. Circulación monetaria}

Para concluir, se estudia en este apartado la procedencia de las distintas piezas recuperadas. De nuevo nos centramos en las tres primeras fases de la secuencia general establecida en la intervención arqueológica. Población: Monedas en las que se ha identificado la ceca o lugar de acuñación, 7 (Piezas $N^{o}$ 1, 2, 3, 4, 5,6 y 7 ).

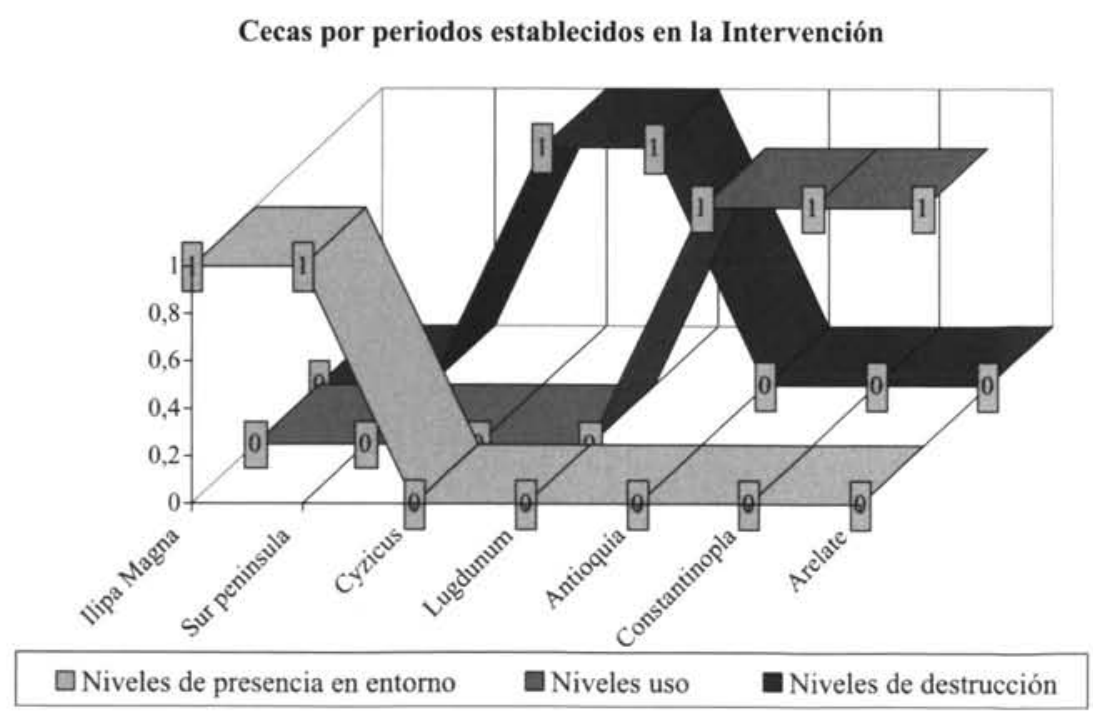

Los momentos más antiguos (niveles de presencia en el entorno) vienen representados por emisiones acuñadas en el sur de la Península, concretamente Alcalá del Río (Pieza 1) y algún otro lugar no concreto 
del mediodía peninsular (Pieza 2); área de acuñación que se estima para esa serie de semis romanorepublicanos de imitación (Arévalo y Campo 1998: 318-325) que aparecen en el territorio de la Ulterior durante el siglo I a. C.

Durante el segundo momento, uso de la estructura bajoimperial, las cecas representadas son las galas y orientales con una mayor proporción de las últimas para, en un último momento, volver a estar presentes ambas áreas de acuñación pero ya en proporciones similares.

La Figura 7 muestra la dispersión geográfica de las cecas documentadas en la intervención y el carácter extraterritorial del circulante documentado. 


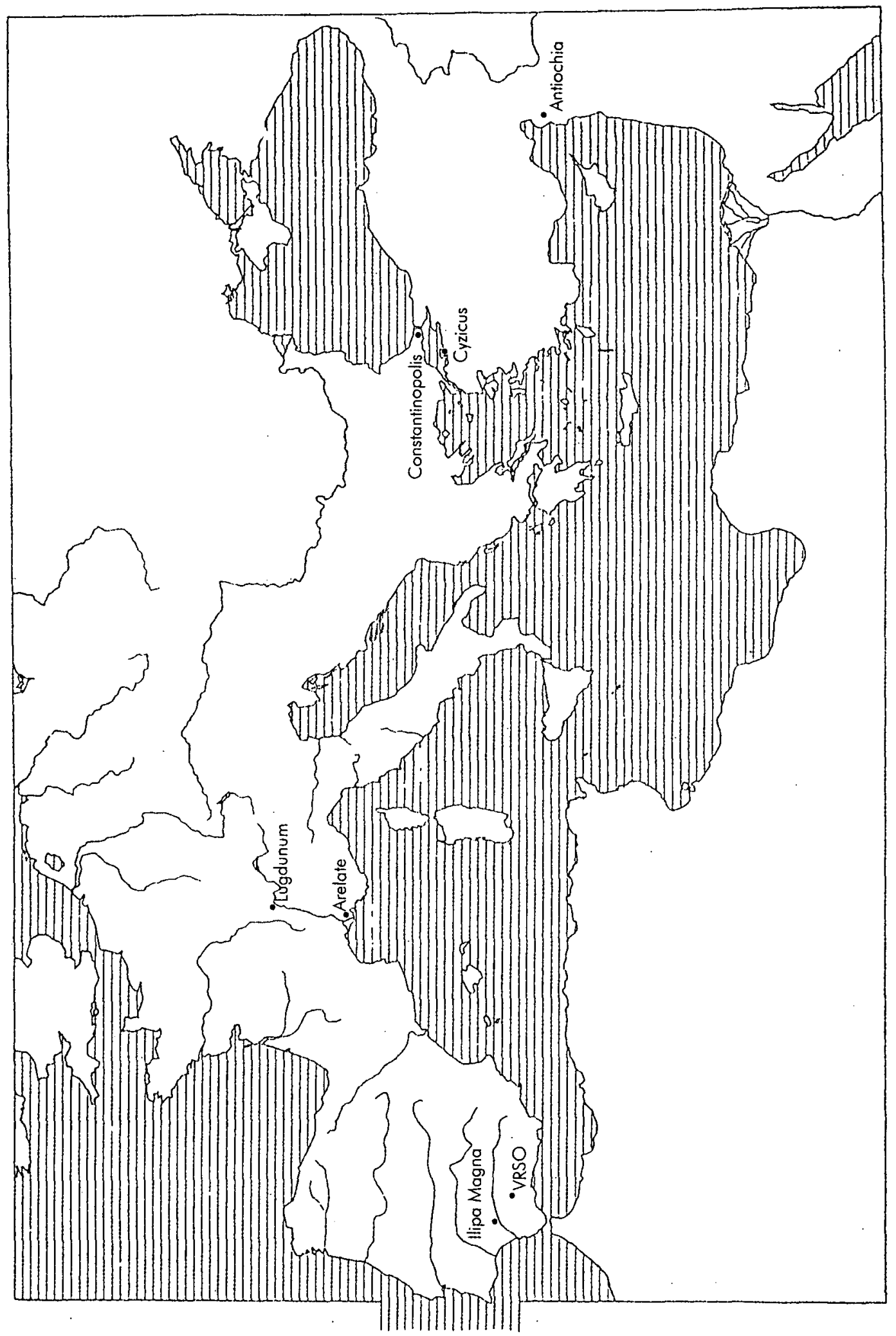

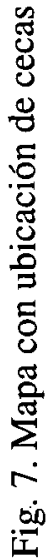




\section{BIBLIOGRAFÍA:}

ARÉVALO, A. y CAMPO, M. (1998): "Las emisiones romanas y sus imitaciones en Hispania durante la república", VV.AA., Historia Monetaria de Hispania Antigua: 318-325, Madrid.

CHAVES TRISTÁN, F. (1998): “Amonedación de las cecas latinas de la Hispania Ulterior”, VV.AA., Historia Monetaria de Hispania Antigua: 270-272, Madrid.

FERNÁNDEZ FLORES, A. (2000): Valoración arqueológica de la secuencia estratigráfica documentada en calle Tesoreros $n^{\circ} 6$ y Santa Clara 3 de Osuna, (Sevilla). Sevilla, informe realizado para la Delegación Provincial de Cultura, inédito.

JIMÉNEZ BARRIENTOS, J.C. y SALAS ÁLVAREZ, J.A. (1997): "Estado actual de la arqueología de Osuna", Studia Historica. Historia Antigua 15: 9-34.

LEDESMA GÁMEZ, F. (1998): Las Murallas de Osuna. Restos Materiales y Fuentes Documentales. Sevilla, tesis de licenciatura inédita, Universidad de Sevilla.

LERDO DE TEJADA PÉREZ DE AYALA, J.M.; GARCÍA SORIA, J.A.; ROLDÁN PÉREZ, J.M. y RUBIO NARVÁEZ, Ma J. (1992): "Desarrollo de la trama urbana de la ciudad de Osuna y caracteres generales del caserío", Hijo del Entendimiento. Homenaje a don Alfredo Malo, catedrático en Osuna: 119-140, Osuna, Asociación de Antiguos Alumnos del I.N.E.M. Francisco Rodríguez Marín de Osuna.

MARCOS ALONSO, C. (Ene-Jun 1996): "Aportación a la circulación de las imitaciones de divisores romanorepublicanos en la península Ibérica", Numisma 237: 199-223.

MAROT, T. (1999): "La ciudad de Barcino durante los siglos V y VI: nuevas aportaciones sobre el circulante", Anejos AEspA XX: 415-422.

MAROT, T. y LLORENS, M.M. (1995): "La Punta de l'Illa de Cullera: Aproximación a la circulación monetaria durante el siglo VI en el área valenciana", Anejos AEspA XIV: 253-261.

MARTÍN GÓMEZ, C. (1982): "Placas decoradas de época paleocristiana y visigoda, con inscripción, del Museo Arqueológico de Sevilla", Museos 1: 37-43.

MIURA ANDRADES, J.M. (1995): "Las órdenes religiosas en Osuna y su entorno hasta fines del siglo XVI", Rodríguez Iglesias, J.J. y García Fernández, M. (eds.), Osuna entre los Tiempos Medievales y Modernos (Siglos XIII-XVIII): 337-361, Sevilla, Universidad de Sevilla.

ORIA SEGURA, M. (en prensa): "Aplique de bronce procedente de la excavación arqueológica en C/. La Huerta (Osuna, Sevilla)", Apuntes 2. Apuntes y Documentos para una Historia de Osuna, 4.

RUIZ CECILIA, J.I. (1998): "Seguimiento arqueológico en la Cuesta de los Cipreses, Osuna (Sevilla), 1998/99”, AAA'98 III 2: 1062-1073.

RUIZ CECILIA, J.I. y FERNÁNDEZ FLORES, A. (1999a): Memoria de la Intervención Arqueológica en calle La Huerta 3 y 5, Osuna (Sevilla). Sevilla, Delegación Provincial de Cultura, inédita.

- (1999b): "Intervención arqueológica de urgencia en C/ La Huerta 3 y 5, Osuna (Sevilla), 1999", $A A A^{\prime}$ '99 III 2: 1041-1053.

- (2000): "Resultados de la intervención arqueológica de urgencia en calle La Huerta $\mathrm{n}^{\circ} 3$ y 5 de Osuna", Apuntes 2. Apuntes y Documentos para una Historia de Osuna 3: 181-192.

SAEZ BOLAÑO, J. A. y BLANCO VILLERO, J. M. (2001): Las Monedas de la Bética Romana, II (conventus Hispalensis), San Fernando.

SALAS ÁLVAREZ, J.A. y PÉREZ RANGEL, J.A. (1988): "Intervención arqueológica de urgencia en la Torre del Agua (Osuna, Sevilla)”, AAA'88 III: 386-391. 
SÁNCHEZ GIL DE MONTES, J. y SALAS ÁLVAREZ, J.A. (1996): "Intervención arqueológica de urgencia en el solar de C/. Asistente Arjona 6-8, Osuna (Sevilla). El arrabal Oeste de la ciudad almohade de Uxuna", AAA'96: 677-687.

VARGAS, J.M.; ROMO, A.S. y GARCÍA, Mª I. (1993): “Aproximación a los modelos de asentamiento en el ámbito sureste de la cora de Écija", Actas del III Congreso de Historia "Écija en la Edad Media y Renacimiento", Sevilla, Universidad de Sevilla: 14-40.

VILLARONGA, L. (1994): Corupus Nummum Hispaniae ante Augusti Aetatem. Madrid, José A. Herrero S.A.

VIVES Y ESCUDERO, A. (1926): La Moneda Hispánica, 2 tomos. Madrid (reedición 1980).

VV.AA. (1966, 1981, 1972): Roman Imperial Coinage, VII, VIII y IX. London.

VV.AA. (1994): Numismática Española. 1474-1994. Catálogo de todas las monedas emitidas desde los Reyes Católicos hasta Juán Carlos I. Barcelona.

VV.AA. (1998): Historia Monetaria de Hispania Antigua. Madrid. 